\title{
Structural and electrical investigations of MBE-grown SiGe nanoislands
}

\author{
İsa Şeker ${ }^{1} \cdot$ Ali Karatutlu $^{2,3}$ (D) $\cdot$ Osman Gürbüz ${ }^{4} \cdot$ Serhat Yanık $^{5} \cdot$ Yakup Bakış $^{1} \cdot$ Mehmet Karakız $^{6}$
}

Received: 14 September 2017 / Accepted: 4 December 2017 / Published online: 16 December 2017

(C) Springer-Verlag GmbH Germany, part of Springer Nature 2017

\begin{abstract}
SiGe nanoislands were grown by Molecular Beam Epitaxy (MBE) method on Si (100) substrates with comparative growth parameters such as annealing temperature, top Ge content and layer-by-layer annealing (LBLA). XRD and Raman data suggest that annealing temperature, top Ge content and layer-by-layer annealing (LBLA) can overall give a control not only over the amorphous content but also over yielding the strained Ge layer formation in addition to mostly Ge crystallites. Depending on the layer design and growth conditions, size of the crystallites was observed to be changed. Four Point Probe (FPP) Method via Semiconductor Analyzer shows that $100{ }^{\circ} \mathrm{C}$ rise in annealing temperature of the samples with $\mathrm{Si}_{0.25} \mathrm{Ge}_{0.75}$ top layers caused rougher islands with vacancies which further resulted in the formation of laterally higher resistive thin film sheets. However, vertically performed I-AFM analysis produced higher I-V values which suggest that the vertical and horizantal conductance mechanisms appear to be different. Ge top-layered samples gained greater crystalline structure and better surface conductivity where LBLA resulted in the formation of Ge nucleation and tight 2D stacking resulting in enhanced current values.
\end{abstract}

Electronic supplementary material The online version of this article (https://doi.org/10.1007/s00339-017-1448-6) contains supplementary material, which is available to authorized users.

İsa Şeker

isaseker05@gmail.com

Ali Karatutlu

ali@unam.bilkent.edu.tr

1 Bionanotechnology Research and Development Center (BINATAM), Fatih University, Buyukcekmece, 34500 Istanbul, Turkey

2 Materials Science and Nanotechnology Department, UNAM-National Nanotechnology Research Center, Bilkent University, 06800 Ankara, Turkey

3 The Institute of Materials Science and Nanotechnology, Bilkent University, 06800 Ankara, Turkey

4 Department of Physics, Yildız Technical University, Davutpaşa, 34210 Istanbul, Turkey

5 Department of Metallurgical and Materials Engineering, Marmara University, Göztepe, 34722 Istanbul, Turkey

6 Department of Mechatronics Engineering, Cumhuriyet University, 58140 Sivas, Turkey

\section{Introduction}

SiGe nanoislands are considered as one of the key developments for next generation technologies due to their easy processing, excellent properties and compatibility with the existing Si-based microelectronic industry [1-4]. MBEgrown $\mathrm{SiGe}$ heterostructures have attracted great interest owing to their high performance in nanoelectronic circuitry within Complementary Metal Oxide Semiconductor (CMOS) platforms [5]. Moreover, monolithic integration of electronic and optical components of SiGe structures on $\mathrm{Si}$ chips is predicted to enhance the performance and functions of Si Very Large Scale Integrated circuits (VLSI) [6, 7]. Many SiGe-based technologies in commercial use including solar cells, photodetectors and high-mobility transistors and those which are still in research phase such as quantum cascade lasers (QCL) require semiconductor heterojunctions [8-12]. SiGe heteroepitaxy devices can also be used in high-density digital circuitry and sensor applications in a wide range of wavelengths between infrared and microwave regions [13]. Introducing Ge into Si via straining and doping effects makes it a suitable candidate for bandengineered devices [14]. For example, Ge quantum dots can be incorporated in Si epitaxial solar cells to improve long wavelength performance [15]. In addition, SiGe nanocrystals 
can function well as a photo-detector being more compatible with Si than the III-V semiconductors as they have extremely large lattice mismatches $[2,16]$. However, the formation of antiphase boundaries between group III-V and IV semiconductors is still an issue although they are lattice mismatched as in the case of the growth of GaAs on Si $[17,18]$.

SiGe nanoislands utilizing the concept of the selforganization are based on strained-layer heteroepitaxy of semiconductor thin films [19]. Structural, optical and electronic properties of these nanocrystalline islands are heavily affected by growth conditions [20-22]. Surface electrical properties of SiGe nanoislands can be tuned by differentiating the substrate growth temperature, Si buffer layer thickness, Ge content, Ge deposition rate, annealing time, annealing temperature, etc. It also requires great effort to achieve high quality of $\mathrm{Ge}$ or $\mathrm{Si}_{1-x} \mathrm{Ge}_{x}$ hetero-epitaxial layers on Si substrates because of the large $4.17 \%$ lattice mismatch relative to Si [23].

Several techniques such as Ion Beam Sputtering Deposition [24], Rapid Thermal Annealing [25], Chemical Vapor Deposition [26] and RF Magnetron Sputtering [27] are being extensively studied to fabricate high-quality SiGe nanoislands. Among them, MBE has many advantages compared to other techniques in the growth of more uniform large area thin films, formation of dense structure with higher crystalline quality and the ease of controlled and repeatable fabrication of epitaxial SiGe layers.

The present work reports on the fabrication of SiGe nanoislands by MBE method and the investigation of their structural and electrical properties under various layer design and growth conditions. Various parameters such as influence of Ge concentration at cap layer, annealing temperature and the effect of LBLA were applied to alter the morphology of the samples on single couple of samples for each effect. For this purpose, a number of characterization methods have been performed using GI-XRD, HR-SEM and Dispersive Raman Spectroscopy. Moreover, lateral and vertical electrical conduction mechanisms were investigated via two complementary methods: FPP Semiconductor Analysis and I-AFM methods, respectively.

\section{Experimental}

The films are deposited on p-type high resistivity (1-10 Ohm-cm) Si (100) wafer substrates with $2.5 \mathrm{~cm} \times 2.5 \mathrm{~cm} \times$ $500 \mu \mathrm{m}$ dimensions by solid source MBE system. Before the films were deposited, substrates have been cleaned according to the RCA procedures with SC-1, 2 (standard clean) and DHF (diluted hydrofluoric acid) steps. First, Si substrates were immersed into a mixture of $\mathrm{NH}_{4} \mathrm{OH}(25 \%), \mathrm{H}_{2} \mathrm{O}_{2}(30 \%)$ and de-ionized water $\left(\mathrm{DI}-\mathrm{H}_{2} \mathrm{O}\right)$ in the ratio 1:1:5 for $5 \mathrm{~min}$.
Following this, wafers were immediately rinsed in a DI- $\mathrm{H}_{2} \mathrm{O}$ bath for a further $3 \mathrm{~min}$. Second, the substrates were put in a mixture of $\mathrm{HCl}(37 \%), \mathrm{H}_{2} \mathrm{O}_{2}(31 \%)$ and $\mathrm{DI}-\mathrm{H}_{2} \mathrm{O}$ in the ratio of 1:1:6 for $10 \mathrm{~min}$. After this, the wafers were rinsed in the DI- $\mathrm{H}_{2} \mathrm{O}$ bath for $3 \mathrm{~min}$ to eliminate residual ions of the acid. Subsequently, substrates were dried by blowing pure $\mathrm{N}_{2}$ gas. Third, Hydrofluoric acid solution (HF-Dip) that is a mixture of $\mathrm{HF}(40 \%)$ and $\mathrm{DI}-\mathrm{H}_{2} \mathrm{O}$ with ratio 1:20 was used to remove the native oxide from the wafer surface. After rinsing $30 \mathrm{~s}$ and drying with $\mathrm{N}_{2}$ gun, they were immediately put into the load-lock chamber.

After cleaning steps, substrate was positioned on the substrate holder by inserting the magnetic arm through the main chamber. After that, liquid Nitrogen was circulated around the chamber and residual gas analyzer (RGA) was employed to ensure the non-existence of unwanted gas species. Before deposition, base pressure and substrate temperature were set as $3 \times 10^{-10} \mathrm{mbar}$ and $990^{\circ} \mathrm{C}$, respectively. To get rid of the hydrogenated Si surface, substrate was subjected to that temperature for $30 \mathrm{~min}$. In addition, treated surface was properly checked by Reflection High Energy Electron Diffraction (RHEED) applying $10 \mathrm{keV}$ at a glancing angle around $1^{\circ}$. The four effusion cells, which are loaded with high-purity intrinsic $\mathrm{Si}$ and $\mathrm{Ge}$, were heated up to $1350-1400{ }^{\circ} \mathrm{C}$.

The growth rates of each cell were optimized to obtain the desired values for both mono and co-deposition. Hence, a growth rate of $0.66 \mathrm{~A} \% \mathrm{~s}$ in total was adjusted by quartz crystal microbalance (QCM). For homogenous coating, sample holder was rotated at $10 \mathrm{rpm}$.

Four samples grown in accordance with two different group layer designs, which are depicted in Fig. 1, are named as $\mathrm{SiGe}-1, \mathrm{SiGe}-2, \mathrm{SiGe}-3$, and SiGe-4. The different colors indicate the particular $\mathrm{Si}-\mathrm{Ge}$ content in the corresponding layer. SiGe-1,2 and $\mathrm{SiGe}-3,4$ samples have been grown with the top Ge contents of 75 and $100 \%$, respectively. The main reason for this layer design is to obtain clear difference in surface topography and roughness under various growth, annealing and layer content conditions to compare their role on electrical resistivity and conductivity.

Growth conditions of the investigated samples have been changed to study their effects on structural and electrical properties. The main growth parameters are quoted in Table 1. From left to right, the columns report sample name, growth temperature, annealing temperature, annealing time and LBLA process. SiGe-1 and SiGe- 2 were grown with varying annealing temperatures of 750 and $850{ }^{\circ} \mathrm{C}$, respectively. SiGe-3 sample was annealed after the completion of the deposition process whereas in SiGe-4, LBLA was applied after the deposition of each individual layer repeatedly as shown in Table 1.

GI-XRD measurements were carried out by XRD Smart Lab Rigaku with $\mathrm{Cu}$ target wavelength $\lambda=1.54 \AA$ at a glancing angle of $5^{\circ}$. HR-SEM images were taken by 
Fig. 1 Comparative layer design of $\mathrm{Si}_{1-x} \mathrm{Ge}_{x}$ samples by gradual Ge content change

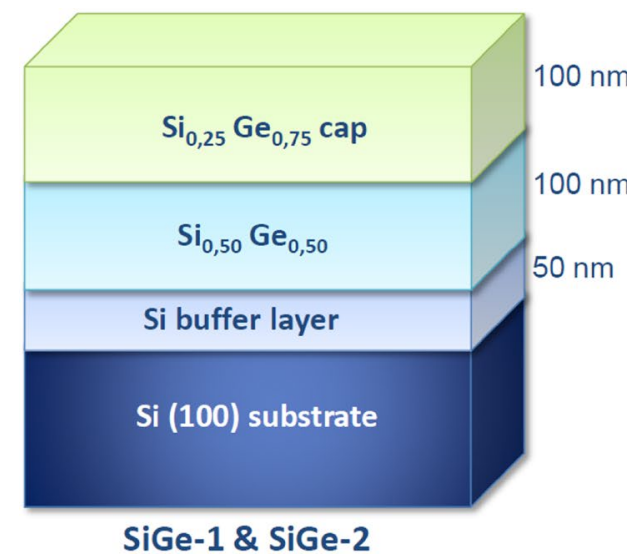

Table 1 Growth conditions of $\mathrm{Si}_{1-x} \mathrm{Ge}_{x}$ thin films

\begin{tabular}{lllll}
\hline $\begin{array}{l}\text { Sample } \\
\text { name }\end{array}$ & $\begin{array}{l}\text { Growth } \\
\text { temperature } \\
\left({ }^{\circ} \mathrm{C}\right)\end{array}$ & $\begin{array}{l}\text { Annealing } \\
\text { temperature } \\
\left({ }^{\circ} \mathrm{C}\right)\end{array}$ & $\begin{array}{l}\text { Annealing } \\
\text { time (min) }\end{array}$ & $\begin{array}{l}\text { LBLA? Yes/ } \\
\text { no }\end{array}$ \\
\hline SiGe-1 & 700 & 750 & 30 & $\mathrm{~N}$ \\
$\mathrm{SiGe}-2$ & 700 & 850 & 30 & $\mathrm{~N}$ \\
$\mathrm{SiGe}-3$ & 700 & 850 & 30 & $\mathrm{~N}$ \\
$\mathrm{SiGe}-4$ & 700 & 850 & 30 & $\mathrm{Y}$ (3 times) \\
\hline
\end{tabular}

field emission JEOL SEM 7001F at $15-20 \mathrm{kV}$ acceleration voltages in secondary electron imaging (SEI) mode. Raman spectroscopy measurements were held by Thermo Scientific DXR Raman spectroscopy system with a $532 \mathrm{~nm}$ laser excitation at $3 \mathrm{~mW}$ laser output power. I-AFM measurements were done by a Pt-coated conductive tip in contact mode using Park Systems XE-100E. As a final investigation, semiconducting analysis was performed with Keithley 4200-SCS Model FPP Semiconductor Analyzing System. The average crystallite sizes were calculated using major $\mathrm{Ge}$ (111) peaks in XRD spectra by Scherrer's equation, from top view SEM images by graphics software Image J; and using phonon confinement model fitted to the $\mathrm{Ge}-\mathrm{Ge}$ TO modes in each Raman data.

\section{Results and discussion}

Microstructures of the films were analyzed by HR-SEM as shown in Fig. 2. SiGe-1 has closely stacked islands where those in $\mathrm{SiGe}-2$ appear in the shape of more isolated buds due to $100{ }^{\circ} \mathrm{C}$ higher annealing temperature than SiGe-1. Stranski-Krastanov mode of island growth is clearly apparent in the cross-sectional SEM image of SiGe-4 in Fig. 2d as 2D film growth is followed by 3D island formation [28]. The LBLA process that is applied to SiGe-4 resulted in the formation of greater islands than those in SiGe-3. Ge crystal facets [29] of SiGe-4 islands with various orientations can be seen in the cross-sectional image of SiGe-4 (d). The various orientations of SiGe-4 sample was also shown in Figure S1.

GI-XRD intensity peaks of $\mathrm{Si}$ and Ge crystalline planes are indicated in Fig. 3. Si (311) and Si (222) peaks are detected from bare substrate with the same glancing angle. Proximity of Si (220) and Ge (220) peaks evidences the formation of SiGe nanocrystalline matrixes [30]. It is distinguishable that $\mathrm{Si}_{1-x} \mathrm{Ge}_{x}$ content of top layer has direct influence on the related intensities of the samples. SiGe-2 has relatively low Ge peak intensities that could be explained by the presence of amorphized segments [31] between nanocrystalline domains originated from excess annealing temperature. Slight Si (222) peak backshifts of SiGe-1, 2, and 3 samples from the free substrate value of $60.3^{\circ}$ indicate the existence of compressive strain induced in thin film layers [32]. However, in SiGe-4 strain induced is relieved by misfit dislocation due to the LBLA applied on the sample.

The average crystallite size, $D$, of each sample was calculated by analyzing the diffraction peaks using Scherrer's Eq. (1):

$D=\frac{K \lambda}{\beta \cos \theta}$

where $\lambda$ is the wavelength of the radiation, $K$ is a dimensionless shape factor equal to 0.89 for spherical nanoparticles, $\beta$ is line broadening of the full width at half maximum (FWHM) in radians and $\theta$ is the Bragg angle peak position. The size of each sample obtained using XRD, SEM, and Raman data are shown in Table 2. The mean particle size from the top view SEM images of SiGe nanoilands and those estimated from the XRD and the Raman data indicate as expected that $\mathrm{Ge}$ crystallite sizes are larger compared to $\mathrm{Si}$ crystallite size since the same stoicmetric ratio were utilized. This result suggests that some portion of the samples could possess amorphous contents. In comparison with the size found by the XRD and Raman data analyses, the size 
Fig. 2 HR-SEM images of SiGe nanoislands: capitalized (A-D) and small words (a-d) represent the top and crosssectional views of the samples, respectively
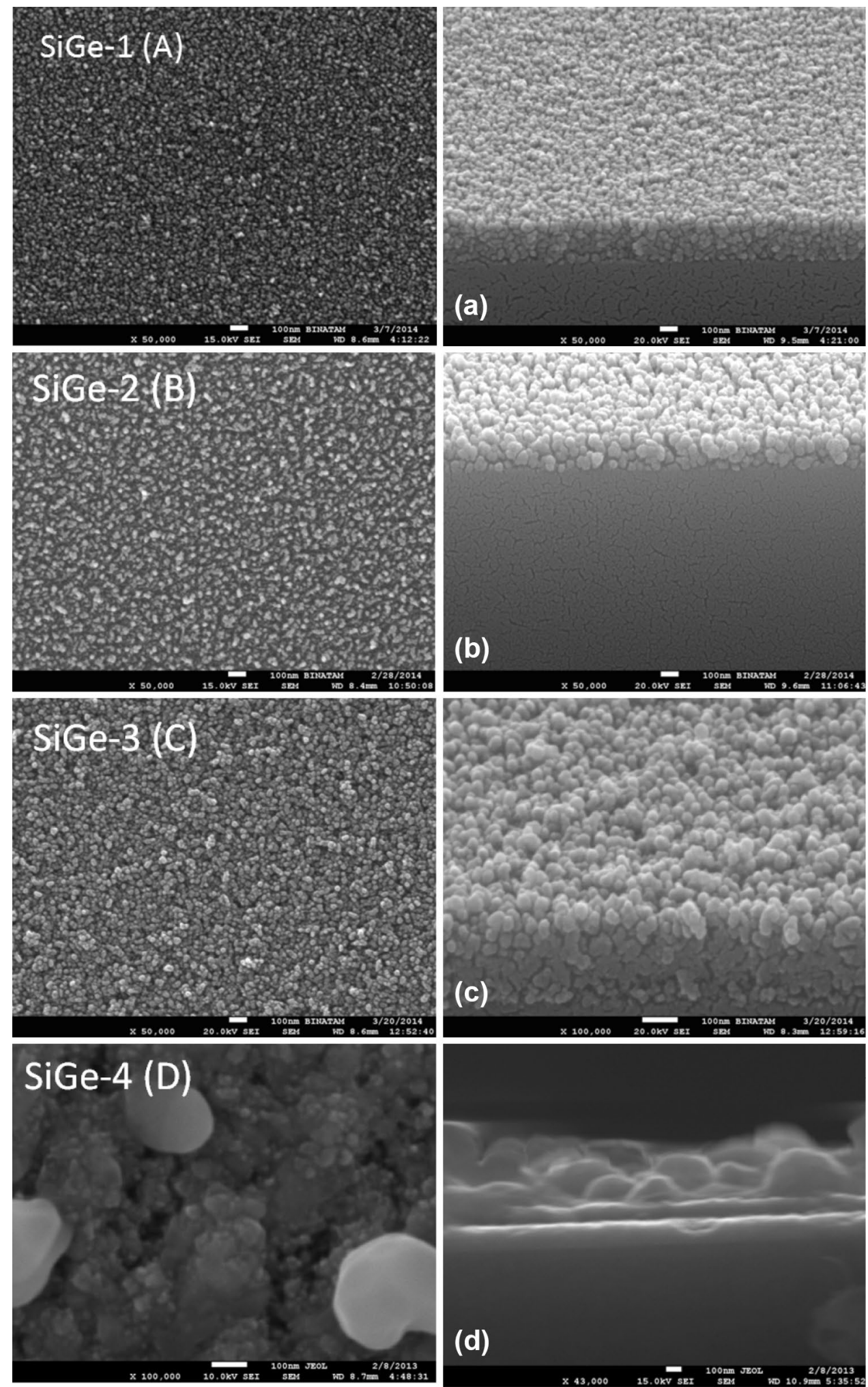

found by the XRD can be considered to be more reliable due to fact that X-rays have relatively higher penetration depth with respect to the laser light used in the Raman measurement $[33,34]$. Furthermore, the size found using the phonon confinement model (PCM) [35, 36] includes estimation only for $\mathrm{Ge}-\mathrm{Ge}$ located at ca. $300 \mathrm{~cm}^{-1}$ due to fact that all Si-Si vibration modes were not observed. Still, the PCM based on 
Fig. 3 GI-XRD spectra of SiGe thin films

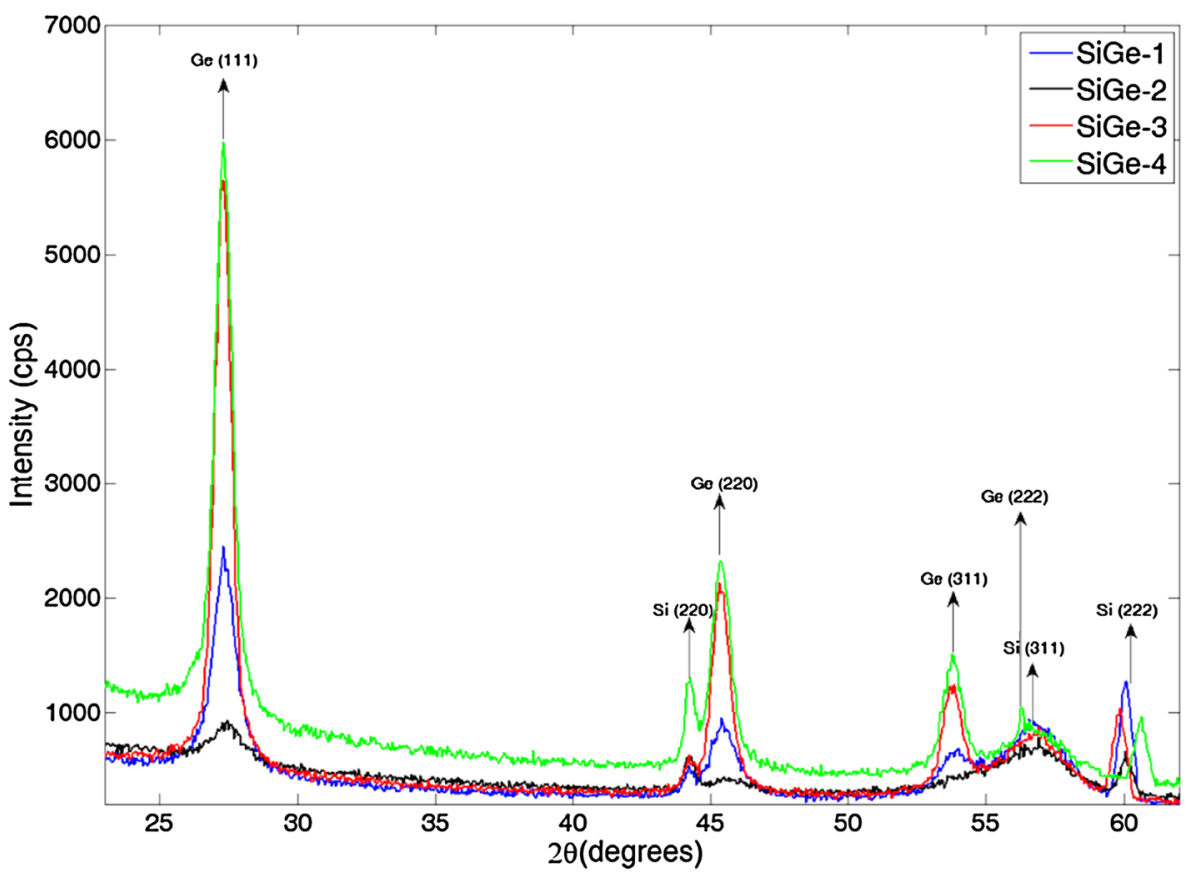

Table 2 Crystallite size calculation of the samples

\begin{tabular}{llll}
\hline & $\begin{array}{l}\text { The crystallite size calculated } \\
\text { from XRD spectra }(\mathrm{nm})\end{array}$ & $\begin{array}{l}\text { Overall nanoparticle size meas- } \\
\text { ured from SEM images }(\mathrm{nm})\end{array}$ & $\begin{array}{l}\text { The Ge crystallite size esti- } \\
\text { mated from Raman spectra } \\
(\mathrm{nm})\end{array}$ \\
\hline $\mathrm{SiGe}-1$ & 9.02 & 13.53 & 5.3 \\
$\mathrm{SiGe}-2$ & 7.53 & 11.78 & 9.44 \\
$\mathrm{SiGe}-3$ & 12.81 & 16.11 & 8.02 \\
$\mathrm{SiGe}-4$ & 12.44 & 19.35 & 9.33 \\
\hline
\end{tabular}

the Raman data were used to have relatively a quick insight on the overall crystallite size.

$\mathrm{Si}-\mathrm{Si}$ vibration peaks arisen from substrates are apparent in SiGe-1 and SiGe-2 at around $518 \mathrm{~cm}^{-1}$. The clear difference of $\mathrm{Si}-\mathrm{Si}$ vibration signals of these samples can be explained by the higher surface roughness of SiGe- 2 that enable the passage of stronger laser beam to substrate that is apparent in the SEM image of Fig. 4b. It is also noticeable that the slight local $\mathrm{Si}-\mathrm{Si}$ vibrations shoulder observed at $455 \mathrm{~cm}^{-1}$ in both samples may have emerged since the layers are grown extremely thicker compared to a few atomic layers [33, 34, 37]. However, due to rich top Ge content in $\mathrm{SiGe}-3$ and $\mathrm{SiGe}-4, \mathrm{Si}-\mathrm{Si}$ vibration peaks are not observed at all since it is possible that Raman signal from lower layers were surpassed by the $100 \mathrm{~nm}$ top Ge layer.

Si-Ge peaks, on the other hand, are located at 392 and $397 \mathrm{~cm}^{-1}$, respectively, in $\mathrm{SiGe}-1$ and $\mathrm{SiGe}-2$. The reason why both samples have the related Si-Ge Raman active optical phonons can be explained by the existence of epitaxial SiGe layers obtained by suitable top $\mathrm{SiGe}$ content. Furthermore, peak intensity ratios of $\mathrm{Si}-\mathrm{Ge}$ to $\mathrm{Ge}-\mathrm{Ge}$

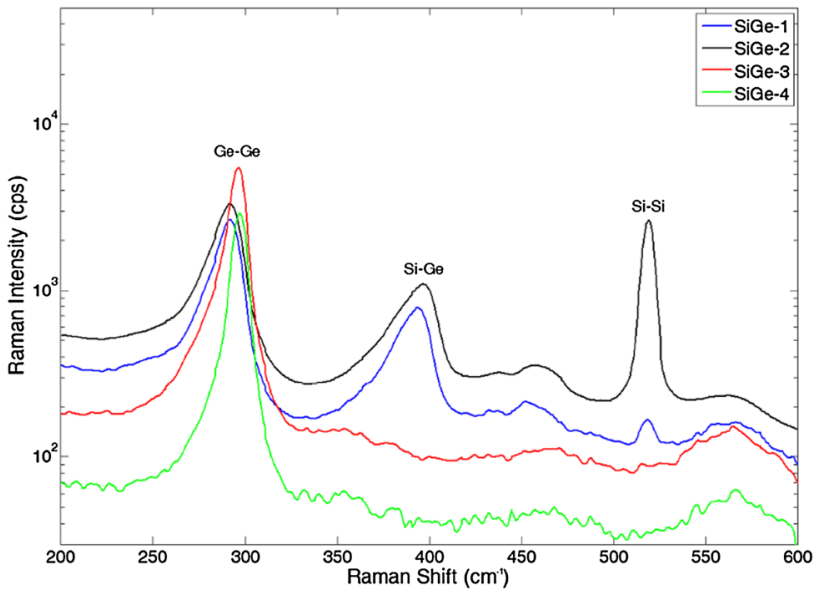

Fig. 4 Dispersive Raman spectra of samples

optical phonon vibrations of SiGe-1 and SiGe-2, which show that the degree of intermixing and heteroepitaxy are calculated as 0.29 and 0.33 , respectively [38]. 
We, furthermore, investigated the structure of Ge crystallites in SiGe nanoislands using PCM fitted to $\mathrm{Ge}-\mathrm{Ge}$ TO phonon mode located below the mode found in a bulk $\mathrm{Ge}$ sample $\left(302 \mathrm{~cm}^{-1}\right)$. The Raman data in Fig. 5a-c suggest that $\mathrm{SiGe}-1, \mathrm{SiGe}-2$ and $\mathrm{SiGe}-3$ appear to contain a-Ge contributions whose peak is located around $275 \mathrm{~cm}^{-1}$ [39]. This is more obvious for SiGe-2 sample which are consistent with the XRD data taken by the GI-XRD technique (see Fig. 3). On the other hand, the Raman data of SiGe-4 promote strain-induced blue shift [40] with no content of amorphous segments.

As electrical investigation, I-V characterization measurements were acquired by FPP and I-AFM methods for lateral and vertical conduction analysis, respectively. In FPP analysis, lateral electrical data is taken by four conductive pins that are gently contacted on the surface of the films without damaging the crystal structure. Since the substrate has high resistivity compared to thin film segment, conduction path is assumed to be within the grown segment as it has been
Table 3 Resistivity and conductivity calculation of the samples

\begin{tabular}{lll}
\hline Sample name & Resistivity $(\Omega \mathrm{cm})$ & Conductivity $(\Omega \mathrm{cm})^{-1}$ \\
\hline SiGe-1 & $3.46 \mathrm{E}+01$ & $2.89 \mathrm{E}-02$ \\
$\mathrm{SiGe}-2$ & $4.37 \mathrm{E}+03$ & $2.29 \mathrm{E}-04$ \\
$\mathrm{SiGe}-3$ & $3.63 \mathrm{E}-01$ & $2.76 \mathrm{E}+00$ \\
$\mathrm{SiGe}-4$ & $2.31 \mathrm{E}-01$ & $4.33 \mathrm{E}+00$ \\
\hline
\end{tabular}

verified by the bare substrate measurement values. It is also ensured that ohmic contact was formed between the pins and the surface without any metal-semiconductor effect. The sheet resistivity of each film was calculated by substituting the observed FPP data in Eq. (2).

$\rho=\frac{\pi}{\ln 2} \times \frac{V}{I} \times t \times k$
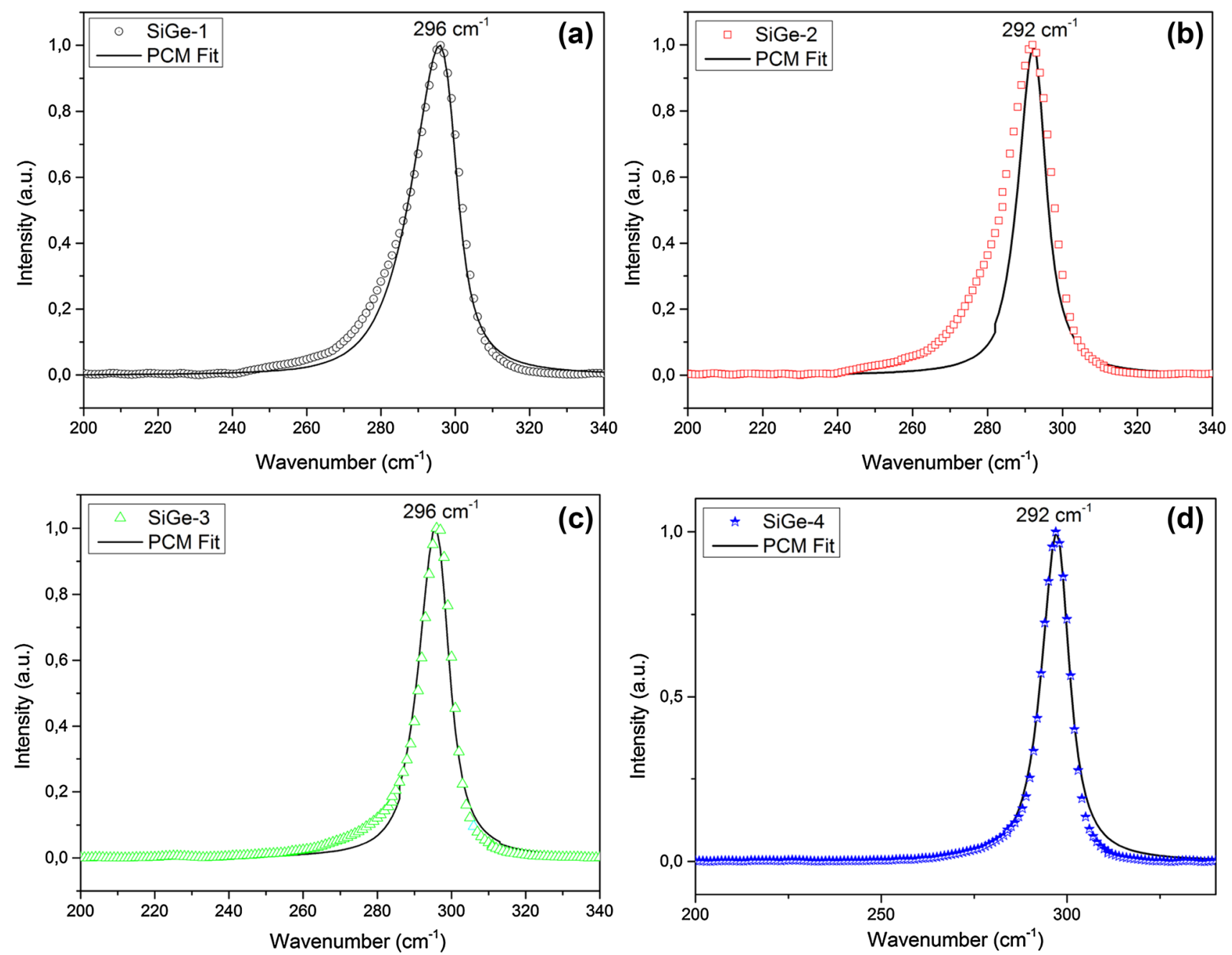

Fig. 5 Raman spectra of a SiGe-1, b SiGe-2, c SiGe-3, and d SiGe-4 over Ge-Ge TO mode and their fits using the PCMs 

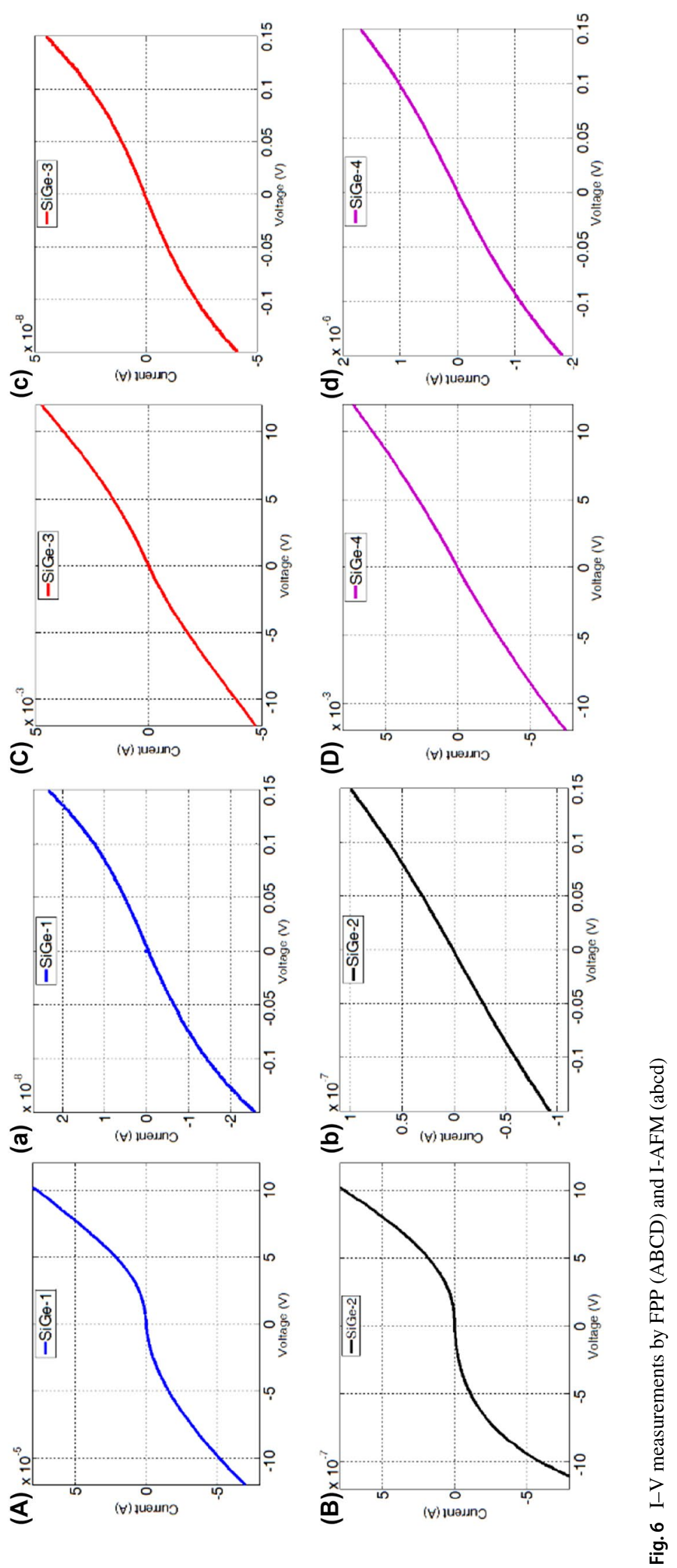
where $\rho$ is the resistivity of the film, $I$ is the current applied between two outer probes, $V$ is the voltage drop across inner probes, and $t$ is the thickness of the film. Then, the electrical conductivities were determined by calculating the reciprocal resistivity as shown in Table 3.

It is apparent that the electrical conductivity increases with increasing $\mathrm{Ge}$ content as seen in Table 3. One can state that conductivity depends not only on Ge concentration, but also crystalline structure quality. In the XRD spectra, good crystalline structure is specified by narrow FWHM values of the diffraction peaks. As a result, the films that have small FWHM values, namely, SiGe-1-3-4, also have good conducting properties.

$\mathrm{I}-\mathrm{V}$ curves of samples between $\pm 12 \mathrm{~V}$ are depicted in Fig. 6 by capitalized named (ABCD) graphs. Accordingly, current values in the range of $\mu \mathrm{A}$ were measured for $\mathrm{SiGe}-1$ and $\mathrm{SiGe}-2$ where in $\mathrm{SiGe}-3$ and $\mathrm{SiGe}-4, \mathrm{~mA}$ values were obtained. It is obvious that the almost $10^{3}$ times the discrepancy is governed by the content of the

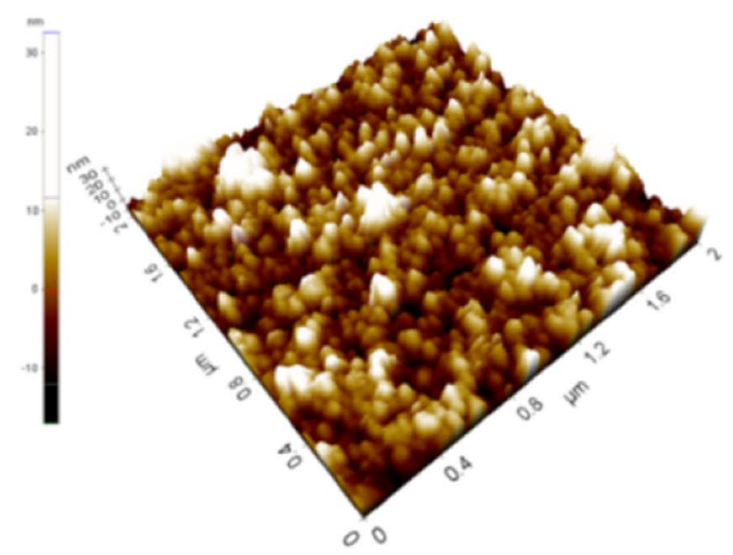

(a) SiGe-1

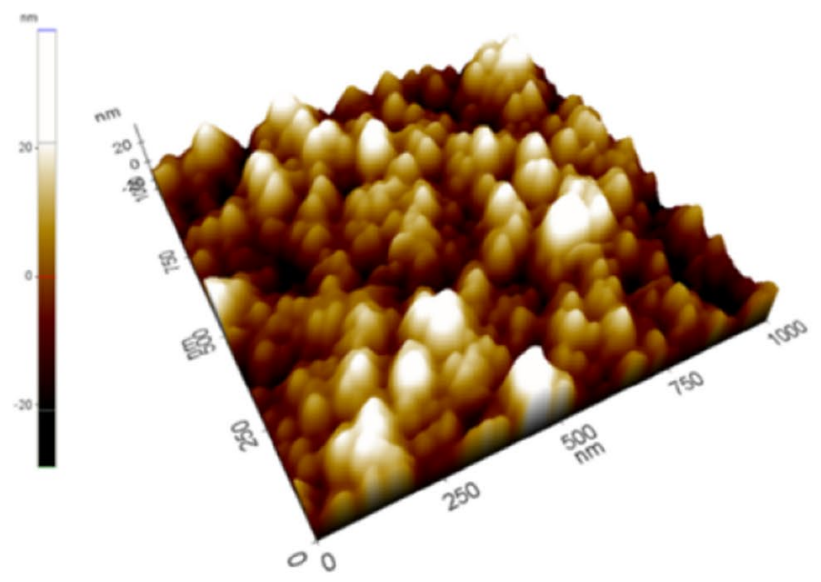

(c) $\mathrm{SiGe}-3$ top layer as $\mathrm{Ge}$ atoms have quite more hole mobility than $\mathrm{Si}$ atoms [38]. Besides, rich crystalline Ge content also enhances the current flow reducing the energy barrier between the valence band and the conduction band [41]. On the other hand, the difference in the current value between SiGe-1 and SiGe-2 lies in the surface topography of these samples. SiGe-2 structure, which has more isolated domes with larger vacancies, does not enable the passage of higher currents on the surface compared to SiGe-1 which has relatively more stacked island structure. I-V measurements taken by I-AFM results are illustrated with small words (abcd) in Fig. 6.

$0.2 \mathrm{~V}$ bias applied to the tip on the depicted AFM topography area segments at various locations in Fig. 7. Average area roughness values of $\mathrm{SiGe}-1-2-3$ is measured around $2-3 \mathrm{~nm}$ range where in SiGe-4 a value of $30 \mathrm{~nm}$ is observed. It is assured that the current pass through a vertical path following the tip, thin film segment and the back-contacted substrate. Hence, a comparative

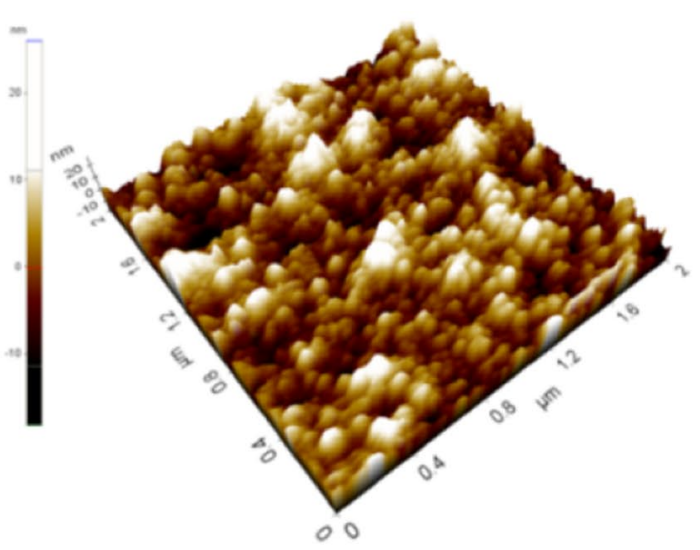

(b) $\mathrm{SiGe}-2$

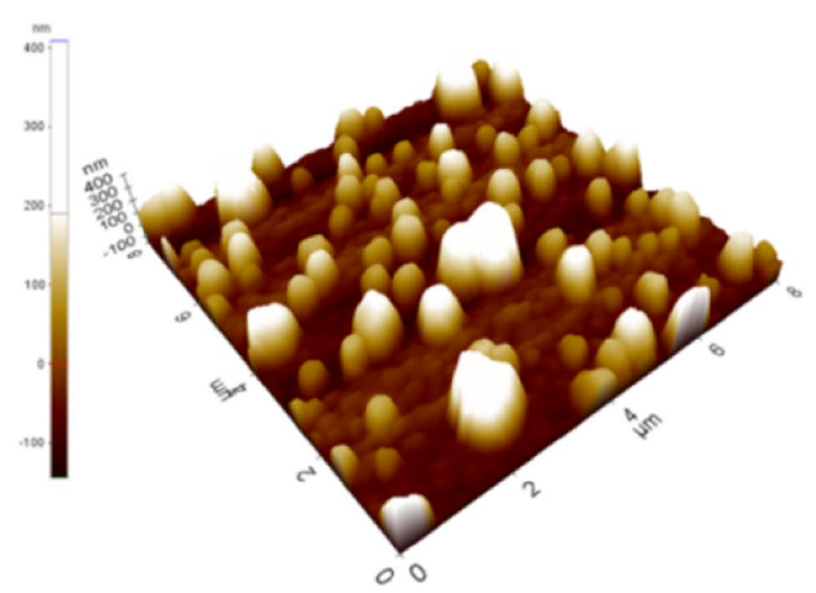

(d) $\mathrm{SiGe}-4$

Fig. 7 I-AFM tip scan area topography images for vertical I-V measurements 
anisotropic set of vertical I-V was obtained as I-AFM tip gently touch the surface without any contact resistance or scratching.

It is noteworthy that $\mathrm{SiGe} 1-2-3$ have approximately nA current values where SiGe- 4 by far apart has $\mu \mathrm{A}$ current range. The large discrepancy in $\mathrm{I}-\mathrm{V}$ enhancement of SiGe-4 may be explained by the difference in vertical surface topography rather than the layer content. It is apparent in the cross-sectional SEM images that SiGe-4 has a thick closely stacked 2D growth segment of approximately $200 \mathrm{~nm}$ where total islanded growth is valid for the rest of the samples. It is possible that, misfit dislocations and amorphous domains which lie on the boundaries of the nanocrystalline $\mathrm{SiGe}-1-2-3$ grains resulted in poorer vertical current values than $\mathrm{SiGe}-4$ along with the high resistivity substrates.

\section{Conclusion}

In this study, the effects of annealing temperature, top Ge content and LBLA on structural and electrical properties of MBE-grown SiGe nanoislands were determined. $100{ }^{\circ} \mathrm{C}$ annealing temperature difference of SiGe-2 than SiGe-1 resulted in the formation of more isolated nanoislands with larger vacancies. Morphology of nanoislands affected the crystalline quality which led the poorer lateral electrical conductivity. The excess temperature yielded the lowest conductivity value for $\mathrm{SiGe}-2$ due to the vacant nature of its nanoislands. The top layer design with a $25 \% \mathrm{Ge}$ difference on $\mathrm{Si}_{0.5} \mathrm{Ge}_{0.5}$ layer played a predominant role in their electrical properties. The samples with $100 \%$ Ge top layers gained barely higher $\mathrm{I}-\mathrm{V}$ values than those with $\mathrm{Si}_{0.25} \mathrm{Ge}_{0.75}$ capped ones as Ge has quite higher electrical conductance and greater crystallite sizes compared to Si. LBLA-applied SiGe-4 sample had shown the formation of larger sized dome features and sharp facets compared to SiGe-3. Islanded morphology became more effective in the lateral $\mathrm{I}-\mathrm{V}$ of $\mathrm{SiGe}$ 1-2 group whereas in SiGe-3 group it is observed that the morphology became more predominant in vertical I-V values. In summary, it can clearly be stated that the content and the morphology of SiGe nanoislands can be altered by highly controlled fabrication parameters. Thus, structural, laterally and horizontally changing electrical properties of these nanoislands can efficiently be tuned with the suitable layer design and growth parameters.

Acknowledgements This work was supported by Fatih University Research Council under the Project number of P500661201_B (2170). All the experimental studies were carried out in Bionanotechnology Research and Development Center (BINATAM).

\section{References}

1. S.W. Bedell, A. Khakifirooz, D.K. Sadana, Strain scaling for CMOS. MRS Bull. 39, 131-137 (2014). https://doi.org/10.1557/ mrs.2014.5

2. W. Hu, B. Cheng, C. Xue, S. Su, H. Xue, Y. Zuo et al., Geon-Si for Si-based integrated materials and photonic devices. Front Optoelectron. 5, 41-50 (2012). https://doi.org/10.1007/ s12200-012-0200-2

3. M. Klemenc, T. Meyer, H. von Kanel, Si surface band-gap shift on top of buried Ge quantum dots. Appl. Surf. Sci. 166, 268-272 (2000). https://doi.org/10.1016/S0169-4332(00)00404-9

4. J. Michel, J. Liu, L.C. Kimerling, High-performance Ge-on-Si photodetectors. Nat. Photonics 4, 527-534 (2010). https://doi. org/10.1038/nphoton.2010.157

5. M.L. Lee, E.A. Fitzgerald, M.T. Bulsara, M.T. Currie, A. Lochtefeld, Strained $\mathrm{Si}, \mathrm{SiGe}$, and Ge channels for high-mobility metal-oxide-semiconductor field-effect transistors. J. Appl. Phys. 97, 11101 (2005). https://doi.org/10.1063/1.1819976

6. K.L. Wang, D. Cha, J. Liu, C. Chen, Ge/Si self-assembled quantum dots and their optoelectronic device applications. Proc. IEEE 95, 1866-1883 (2007). https://doi.org/10.1109/ JPROC.2007.900971

7. K. Ma, R. Chen, D.A.B. Miller, J.S. Harris, Novel on-chip fully monolithic integration of GaAs devices with completely fabricated Si CMOS circuits. IEEE J. Sel. Top Quantum Electron 11, 1278-1283 (2005). https://doi.org/10.1109/JSTQE.2005.860991

8. R. Oshima, Y. Watanabe, M. Yamanaka, H. Kawanami, I. Sakamoto, K. Matsubara et al., High-quality SiGe films grown with compositionally graded buffer layers for solar cell applications. J. Cryst. Growth 378, 226-229 (2013). https://doi.org/10.1016/j. jerysgro.2012.12.154

9. P. Tomasini, V. Machkaoutsan, S.G. Thomas, Analysis of silicon germanium vapor phase epitaxy kinetics. Thin Solid Films 518, S12-S17 (2010). https://doi.org/10.1016/j.tsf.2009.10.046

10. J. Werner, M. Oehme, M. Schmid, M. Kaschel, A. Schirmer, E. Kasper et al., Germanium-tin p-i-n photodetectors integrated on silicon grown by molecular beam epitaxy. Appl. Phys. Lett. 98, 61108 (2011). https://doi.org/10.1063/1.3555439

11. V. Sorianello, L. Colace, M. Nardone, G. Assanto, Thermally evaporated single-crystal Germanium on Silicon. Thin Solid Films 519, 8037-8040 (2011). https://doi.org/10.1016/j.tsf.2011.06.023

12. D.-J. Xue, J.-J. Wang, Y.-Q. Wang, S. Xin, Y.-G. Guo, L.-J. Wan, Facile synthesis of germanium nanocrystals and their application in organic-inorganic hybrid photodetectors. Adv. Mater. 23, 3704-3707 (2011). https://doi.org/10.1002/ adma. 201101436

13. J.P. Sun, G.I. Haddad, P. Mazumder, J.N. Schulman, Resonant tunneling diodes: models and properties. Proc. IEEE 86, 641660 (1998). https://doi.org/10.1109/5.663541

14. R. Soref, The past, present, and future of silicon photonics. IEEE J. Sel. Top Quantum Electron 12, 1678-1687 (2006). https://doi.org/10.1109/JSTQE.2006.883151

15. I.J. Kuzma-Filipek, F. Duerinckx, E. Van Kerschaver, K. Van Nieuwenhuysen, G. Beaucarne, J. Poortmans, Chirped porous silicon reflectors for thin-film epitaxial silicon solar cells. J. Appl. Phys. 104, 73529 (2008). https://doi. org/10.1063/1.2993753

16. S.P. Tobin, S.M. Vernon, C. Bajgar, V.E. Haven, L.M. Geoffroy, D.R. Lillington, High-efficiency GaAs/Ge monolithic tandem solar cells. IEEE Electron Device Lett. 9, 256-258 (1988). https://doi.org/10.1109/55.708

17. C.S.C. Barrett, A.G. Lind, X. Bao, Z. Ye, K.Y. Ban, P. Martin et al., Quantitative correlation of interfacial contamination and antiphase domain boundary density in GaAs on $\mathrm{Si}(100)$. 
J. Mater. Sci. 51, 449-456 (2016). https://doi.org/10.1007/ s10853-015-9334-0

18. O. Rubel, S.D. Baranovskii, Formation energies of antiphase boundaries in GaAs and GaP: an ab initio study. Int. J. Mol. Sci. 10, 5104-5114 (2009). https://doi.org/10.3390/ijms10125104

19. K. Eberl, O. Schmidt, R. Duschl, O. Kienzle, E. Ernst, Y. Rau, Self-assembling $\mathrm{SiGe}$ and $\mathrm{SiGeC}$ nanostructures for light emitters and tunneling diodes. Thin Solid Films 369, 33-38 (2000). https:// doi.org/10.1016/S0040-6090(00)00830-0

20. J. Stangl, V. Holý, G. Bauer, Structural properties of self-organized semiconductor nanostructures. Rev. Mod. Phys. 76, 725-783 (2004). https://doi.org/10.1103/RevModPhys.76.725

21. C. Tan, H. Zhang, Z.Y. Fang, W. Zhou, Z. Liu, D.G. Mandrus et al., Two-dimensional transition metal dichalcogenide nanosheet-based composites. Chem. Soc. Rev. 44, 2713-2731 (2015). https://doi.org/10.1039/C4CS00182F

22. C. Teichert, Self-organization of nanostructures in semiconductor heteroepitaxy. Phys. Rep. 365, 335-432 (2002). https://doi. org/10.1016/S0370-1573(02)00009-1

23. D.J. Paul, Si/SiGe heterostructures: from material and physics to devices and circuits. Semicond. Sci. Technol. 19, R75-R108 (2004). https://doi.org/10.1088/0268-1242/19/10/R02

24. S. Ke, S. Ye, J. Yang, Z. Wang, C. Wang, Y. Yang, Morphological evolution of self-assembled SiGe islands based on a mixed-phase pre-SiGe island layer grown by ion beam sputtering deposition. Appl. Surf. Sci. 328, 387-394 (2015). https://doi.org/10.1016/j. apsusc.2014.11.034

25. A.M.P. dos Anjos, I. Doi, J.A. Diniz, Structural characterization of SiGe nanoclusters formed by rapid thermal annealing. Appl. Surf. Sci. 254, 6055-6058 (2008). https://doi.org/10.1016/j. apsusc.2008.02.119

26. K.-H. Shim, H. Deok Yang, Y.-H. Kil, J.-H. Yang, W.-K. Hong, J.-J. Kim et al., Characterization of reduced pressure chemical vapor deposited Si0.8Ge0.2/Si multi-layers. Mater. Sci. Semicond. Process 16, 126-130 (2013). https://doi.org/10.1016/j. mssp.2012.06.002

27. A.F. Abd Rahim, M.R. Hashim, N.K. Ali, A.M. Hashim, M. Rusop, M.H. Abdullah, The evolution of Si-capped Ge islands on $\mathrm{Si}(100)$ by RF magnetron sputtering and rapid thermal processing: The role of annealing times. Microelectron. Eng. 126, 134-142 (2014). https://doi.org/10.1016/j.mee.2014.06.026

28. N. Pinto, R. Murri, R. Rinaldi, G. Barucca, Strain-driven morphology of Si1-xGex islands grown on $\mathrm{Si}(100)$. Micron 31, 315-321 (2000). https://doi.org/10.1016/S0968-4328(99)00099-2

29. N. Sustersic, L. Nataraj, C. Weiland, M. Coppinger, M.V. Shaleev, A.V. Novikov et al., Effects of boron and phosphorus doping on the photoluminescence of self-assembled germanium quantum dots. Appl. Phys. Lett. 94, 183103 (2009). https://doi. org/10.1063/1.3114377
30. W. Luo, X. Wang, C. Meyers, N. Wannenmacher, W. Sirisaksoontorn, M.M. Lerner et al., Efficient fabrication of nanoporous Si and $\mathrm{Si} / \mathrm{Ge}$ enabled by a heat scavenger in magnesiothermic reactions. Sci. Rep. 3, 2222 (2013). https://doi.org/10.1038/srep02222

31. G. Sahu, H.P. Lenka, D.P. Mahapatra, B. Rout, F.D. McDaniel, Narrow band UV emission from direct bandgap Si nanoclusters embedded in bulk Si. J. Phys. Condens. Matter 22, 72203 (2010). https://doi.org/10.1088/0953-8984/22/7/072203

32. B. Saha, M. Sharma, A. Sarma, A. Rath, P.V. Satyam, P. Chakraborty et al., Surface and interfacial structural characterization of MBE grown Si/Ge multilayers. Appl. Surf. Sci. 256, 547-551 (2009). https://doi.org/10.1016/j.apsusc.2009.08.031

33. Z. Liu, B. Cheng, W. Hu, S. Su, C. Li, Q. Wang, Enhanced photoluminescence of multilayer Ge quantum dots on $\mathrm{Si}(001)$ substrates by increased overgrowth temperature. Nanoscale Res. Lett. 7, 383 (2012). https://doi.org/10.1186/1556-276X-7-383

34. L. Nataraj, N. Sustersic, M. Coppinger, L.F. Gerlein, J. Kolodzey, S.G. Cloutier, Structural and optoelectronic properties of germanium-rich islands grown on silicon using molecular beam epitaxy. Appl. Phys. Lett. 96, 121911 (2010). https://doi. org/10.1063/1.3371759

35. H. Richter, Z.P. Wang, L. Ley, The one phonon Raman spectrum in microcrystalline silicon. Solid State Commun. 39, 625-629 (1981). https://doi.org/10.1016/0038-1098(81)90337-9

36. I.H. Campbell, P.M. Fauchet, The effects of microcrystal size and shape on the one phonon Raman spectra of crystalline semiconductors. Solid State Commun. 58, 739-741 (1986). https://doi. org/10.1016/0038-1098(86)90513-2

37. T.S. Perova, R.A. Moore, K. Lyutovich, M. Oehme, E. Kasper, Strain, composition and crystalline perfection in thin SiGe layers studied by Raman spectroscopy. Thin Solid Films 517, 265-268 (2008). https://doi.org/10.1016/j.tsf.2008.08.060

38. S.S. Iyer, J.C. Tsang, M.W. Copel, P.R. Pukite, R.M. Tromp, Growth temperature dependence of interfacial abruptness in Si/Ge heteroepitaxy studied by Raman spectroscopy and medium energy ion scattering. Appl. Phys. Lett. 54, 219-221 (1989). https://doi. org/10.1063/1.101014

39. A. Karatutlu, M. Song, A.P. Wheeler, O. Ersoy, W.R. Little, Y. Zhang et al., Synthesis and structure of free-standing germanium quantum dots and their application in live cell imaging. RSC Adv. 5, 20566-20573 (2015). https://doi.org/10.1039/C5RA01529D

40. A.B. Talochkin, A.G. Cherkov, Raman determination of uniformity of multilayer $\mathrm{Si} / \mathrm{Ge}$ structures with Ge quantum dots. Nanotechnology 20, 345702 (2009). https://doi. org/10.1088/0957-4484/20/34/345702

41. S.K. Ray, R.K. Singha, S. Das, S. Manna, A. Dhar, Ge based nanostructures for electronic and photonic devices. Microelectron. Reliab. 50, 674-678 (2010). https://doi.org/10.1016/j. microrel.2010.01.049 